Article

\title{
The Influence of Different Partial Pressure on the Fabrication of InGaO Ultraviolet Photodetectors
}

\author{
Sheng-Po Chang *, Li-Yang Chang and Jyun-Yi Li \\ Institute of Microelectronics \& Department of Electrical Engineering, \\ Center for Micro/Nano Science and Technology, Advanced Optoelectronic Technology Center, \\ National Cheng Kung University, Tainan 70101, Taiwan; leon50108@yahoo.com.tw (L.-Y.C.); \\ z823040@gmail.com (J.-Y.L.) \\ * Correspondence: changsp@mail.ncku.edu.tw; Tel.: +886-6-275-7575 (ext. 62400-1208) \\ Academic Editors: Christos Riziotis, Evangelos Hristoforou and Dimitrios Vlachos \\ Received: 11 October 2016; Accepted: 12 December 2016; Published: 15 December 2016
}

\begin{abstract}
A metal-semiconductor-metal ultraviolet photodetector has been fabricated with a radiofrequency $(\mathrm{RF})$-sputtered $\mathrm{InGaO}$ thin film. Results for the devices fabricated under different oxygen partial pressure are here in discussed. Under low oxygen partial pressure, the devices work in the photoconductive mode because of the large number of subgap states. Therefore, the devices exhibit internal gain. These defects in the films result in slow switching times and lower photo/dark current ratios. A higher flow ratio of oxygen during the sputtering process can effectively restrain the oxygen vacancies in the film. The responsivity of the photodetector fabricated under an oxygen flow ratio of $20 \%$ can reach $0.31 \mathrm{~A} / \mathrm{W}$. The rise time and decay time can reach $21 \mathrm{~s}$ and $27 \mathrm{~s}$, respectively.
\end{abstract}

Keywords: InGaO; photodetector; oxygen partial pressure

\section{Introduction}

Ultraviolet (UV) photodetectors have drawn increasing attention owing to their multiple applications, such as chemical analysis, water purification, flame detection, and secure communications [1-3]. According to the cutoff wavelength, the devices can be divided into visible-blind photodetectors $(\lambda \leq 400 \mathrm{~nm})$ and solar-blind photodetectors $(\lambda \leq 280 \mathrm{~nm})$. For instance, solar-blind sensors applied in the military can be used in missile warning systems and therefore have no natural (sun) false alarm. Visible-blind sensors can be used for studying the ozone layer where UV radiation is intense.

Recently, wide bandgap semiconductors such as $\mathrm{ZnO}, \mathrm{GaN}$, and $\mathrm{TiO}_{2}$ have been commonly investigated owing to their promising advantages such as high sensitivity at room temperature [4-9]. However, indium-gallium-oxide (IGO) is not commonly reported in the literature. IGO is a metal-oxide material with potential. The bandgap of $\operatorname{In}_{2} \mathrm{O}_{3}$ is approximately $2.9 \mathrm{eV}$, approaching the visible-blind region. We can broaden the bandgap of $\operatorname{In}_{2} \mathrm{O}_{3}$ by doping with $\mathrm{Ga}_{2} \mathrm{O}_{3}$ [10], which is usually used in solar-blind photodetectors [11,12] and has a wide bandgap energy of approximately $4.9 \mathrm{eV}$. With $\mathrm{Ga}_{2} \mathrm{O}_{3}$, the oxygen deficiencies of $\mathrm{In}_{2} \mathrm{O}_{3}$ can also be restrained because of the strong bonding between gallium atoms and oxygen atoms.

Wenckstern et al. investigated the optical properties of $\operatorname{In}_{\mathrm{x}} \mathrm{Ga}_{1-\mathrm{x}} \mathrm{O}$ thin films and characteristics of Schottky contacts thereon [13]. Chang et al. reported amorphous IGO UV photodetectors prepared by co-sputtering [14]. The amount of oxygen vacancies in the film often play an important role in the performance of the devices and are always determined by the oxygen partial pressure during the process. However, to date there has still been no research on the influence of different partial pressures on the fabrication of IGO photodetectors. In this study, IGO UV photodetectors based on a metal-semiconductor-metal (MSM) structure have been fabricated under different oxygen partial 
pressures by radiofrequency $(\mathrm{RF})$ magnetron sputtering at room temperature. The performance of the devices and the mechanism of their photoresponse characteristics are studied in detail.

\section{Materials and Methods}

Quartz substrates were cleaned in an ultrasonic bath with acetone, methanol, and deionized water. IGO films of thickness $200 \mathrm{~nm}$ were deposited on the substrate by RF magnetron sputtering at room temperature, using an IGO ceramic sputtering target (atomic ratio In:Ga $=9: 1,99.99 \%$ pure). The RF power was $100 \mathrm{~W}$. The chamber was evacuated below $10^{-6}$ torr. The pressure was 5 mtorr during the process, and the gas flow ratios of $\mathrm{O}_{2} / \mathrm{Ar}$ were $0 \%, 5 \%, 10 \%$, and $20 \%$. Interdigital $\mathrm{Ni} / \mathrm{Au}$ electrodes were deposited by thermal evaporation onto the IGO thin films. With the Ni layer, the contact between the semiconductor and metal was improved. The fingers were $0.1 \mathrm{~mm}$ in width, $1.2 \mathrm{~mm}$ in length, and the inter-finger distance was $0.2 \mathrm{~mm}$. A schematic of an IGO MSM photodetector is illustrated in Figure 1. X-ray diffraction (XRD) of the films was observed using a Rigaku X-ray diffractometer. The absorption coefficient spectra were measured by UV-visible scanning spectrophotometry. The surface smoothness was characterized by an atomic force microscope (AFM). The current-voltage characteristic was measured using an Agilent B1500 semiconductor parameter analyzer. The photoresponse of the photodetector was measured with a monochromator equipped with a $250 \mathrm{~W}$ Xe lamp.

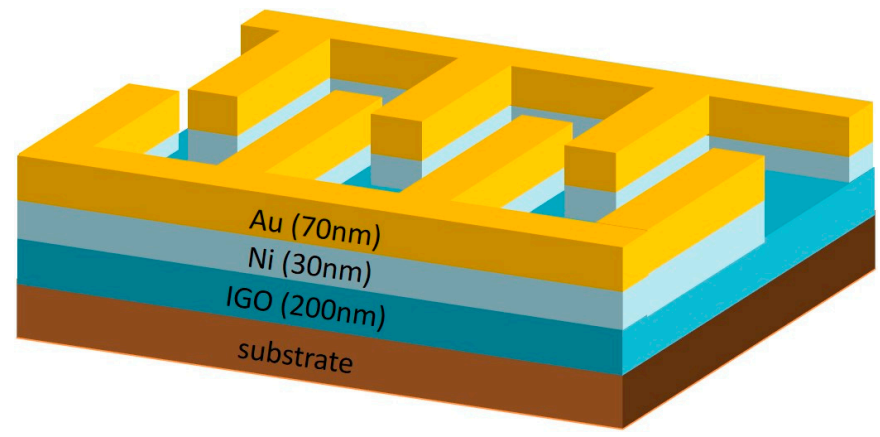

Figure 1. Schematic structure of a metal-semiconductor-metal (MSM) photodetector.

\section{Results and Discussion}

Figure 2 shows XRD patterns of the IGO films. The film is amorphous under $0 \%$ oxygen. Numerous peaks are observed from the samples under higher oxygen partial pressure. The peak intensities increased and the full width at half-maximum (FWHM) decreased as the oxygen partial pressure increased, indicating that the crystalline qualities are improved. The peaks (222), (440), (400), and (622) observed in IGO film fabricated under $20 \%$ oxygen partial pressure are consistent with the phase of $\mathrm{In}_{2} \mathrm{O}_{3}$. It is obvious that the $20 \%$ IGO film shows a polycrystalline phase.

Figure 3 shows AFM images of the IGO films. The scanning areas were $5 \mu \mathrm{m} \times 5 \mu \mathrm{m}$. The root mean square surface roughness of the $5 \%, 10 \%$, and $20 \%$ films were $0.879 \mathrm{~nm}, 1.097 \mathrm{~nm}$, and $1.088 \mathrm{~nm}$, respectively. The smooth surface of the films lead to lower surface density of states, which is beneficial for the performance of the devices [15]. Figure 4 shows optical absorption spectra of the IGO films. The bandgap of IGO is approximately $3.1-3.3 \mathrm{eV}$. The bandgap of the sample fabricated under $20 \%$ rises to $3.3 \mathrm{eV}$, with strong absorption for photons with wavelength shorter than $380 \mathrm{~nm}$. It can be ascribed to the larger binding energy of $\mathrm{GaO}$, and the formation of $\mathrm{GaO}$ decreases the conductivity of the film. The excess oxygen could bind with In atoms stably, leading to the apparent crystalline phase. The results of electrical measurement can also prove this deduction. Transmittance spectra of different partial pressure are shown in Figure S1 of the Supplementary Materials. 


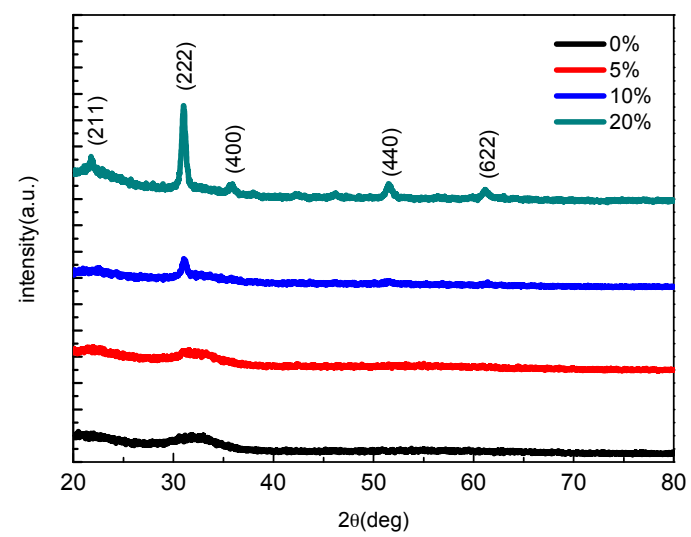

Figure 2. X-ray diffraction (XRD) patterns of the indium-gallium-oxide (IGO) films with different oxygen partial pressure by radiofrequency (RF) magnetron sputtering.

(a)
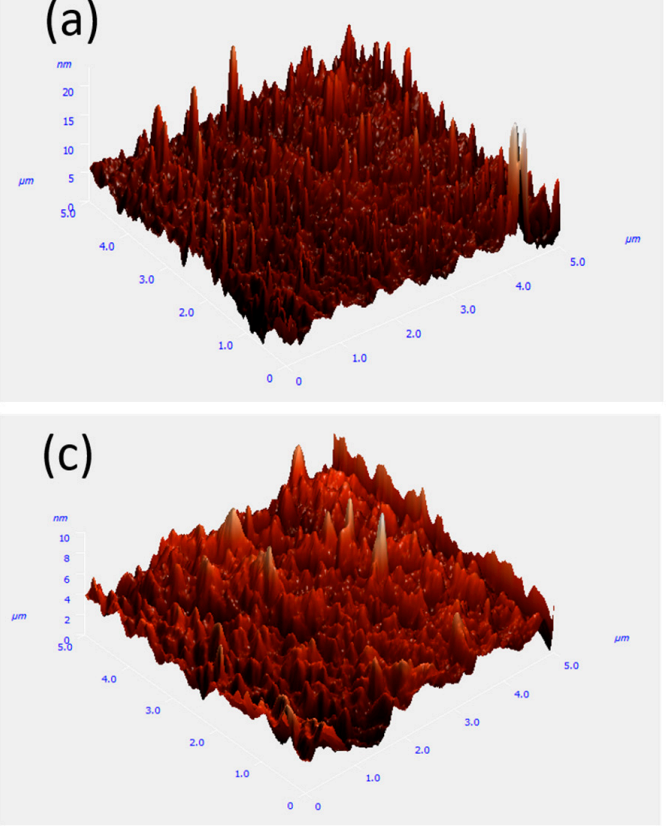
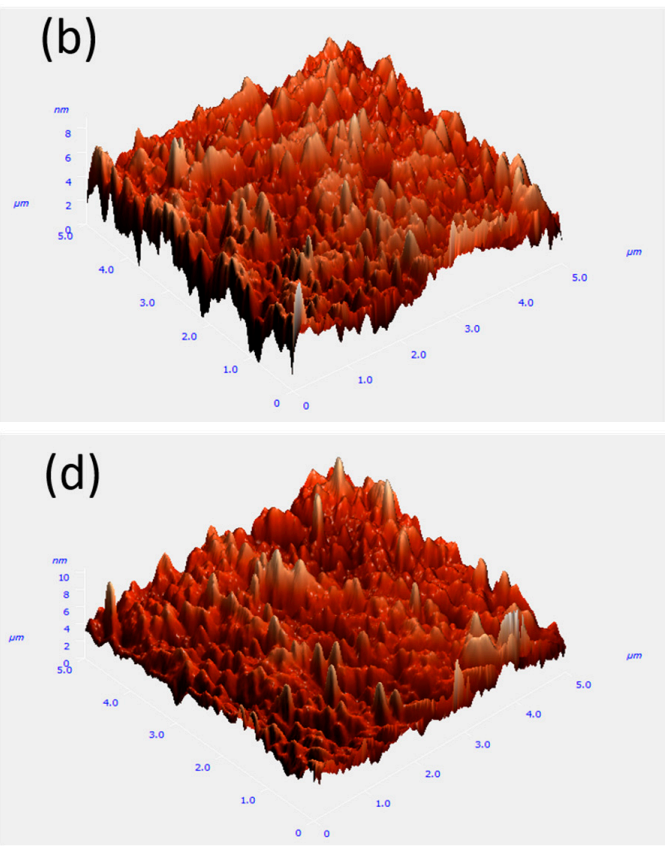

Figure 3. Atomic force microscope (AFM) images of the IGO films sputtered under (a) $0 \%$; (b) $5 \%$; (c) $10 \%$; and (d) $20 \%$.

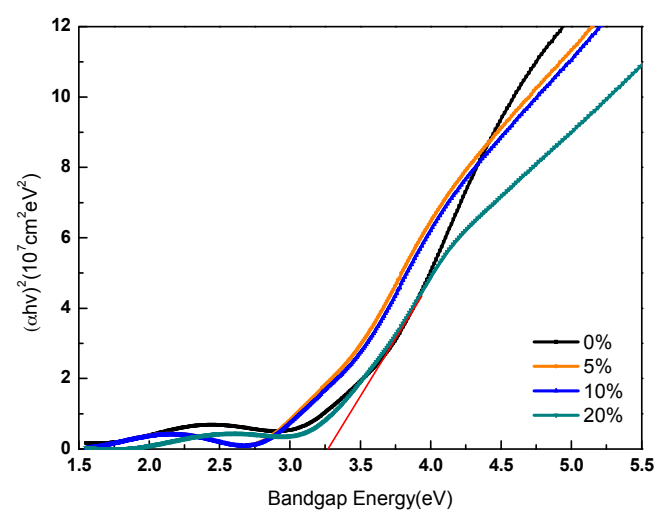

Figure 4. Absorption coefficient spectra of IGO films. 
The chemical composition of the IGO films was investigated by X-ray photoelectron spectroscopy (XPS) measurements. In order to differentiate the XPS measurements, the typical $\mathrm{O}_{1 \mathrm{~s}}$ peak was divided into three peaks through Gaussian fitting, as shown in Figure 5. The deconvoluted results of the $\mathrm{O}_{1 \mathrm{~s}}$ peaks exhibited a peak at around $529.6 \mathrm{eV}\left(\mathrm{O}_{\mathrm{I}}\right)$, which is ascribed to the $\mathrm{O}_{2}{ }^{-}$ions among metal oxides; a second peak, around $531.1 \mathrm{eV}\left(\mathrm{O}_{\mathrm{II}}\right)$, is usually attributed to the oxygen vacancies in the film; the third peak, located at about $531.7 \mathrm{eV}$, is related to weakly bound oxygen species on the film surface, such as $\mathrm{CO}_{3}, \mathrm{OH}^{-}$, or adsorbed $\mathrm{O}_{2}$ [16]. The relative ratio of $\mathrm{O}_{\mathrm{II}} / \mathrm{O}_{\text {total }}$ are $36.4 \%, 35.2 \%, 33.8 \%$, and $28.8 \%$ for $\mathrm{pO}_{2}=0 \%, 5 \%, 10 \%$, and $20 \%$, respectively. As the partial oxygen pressure increases, the oxygen in the chamber tends to fill up the deficiencies in the IGO crystal lattice, leading to remarkable reduction in the vacancies in the film.
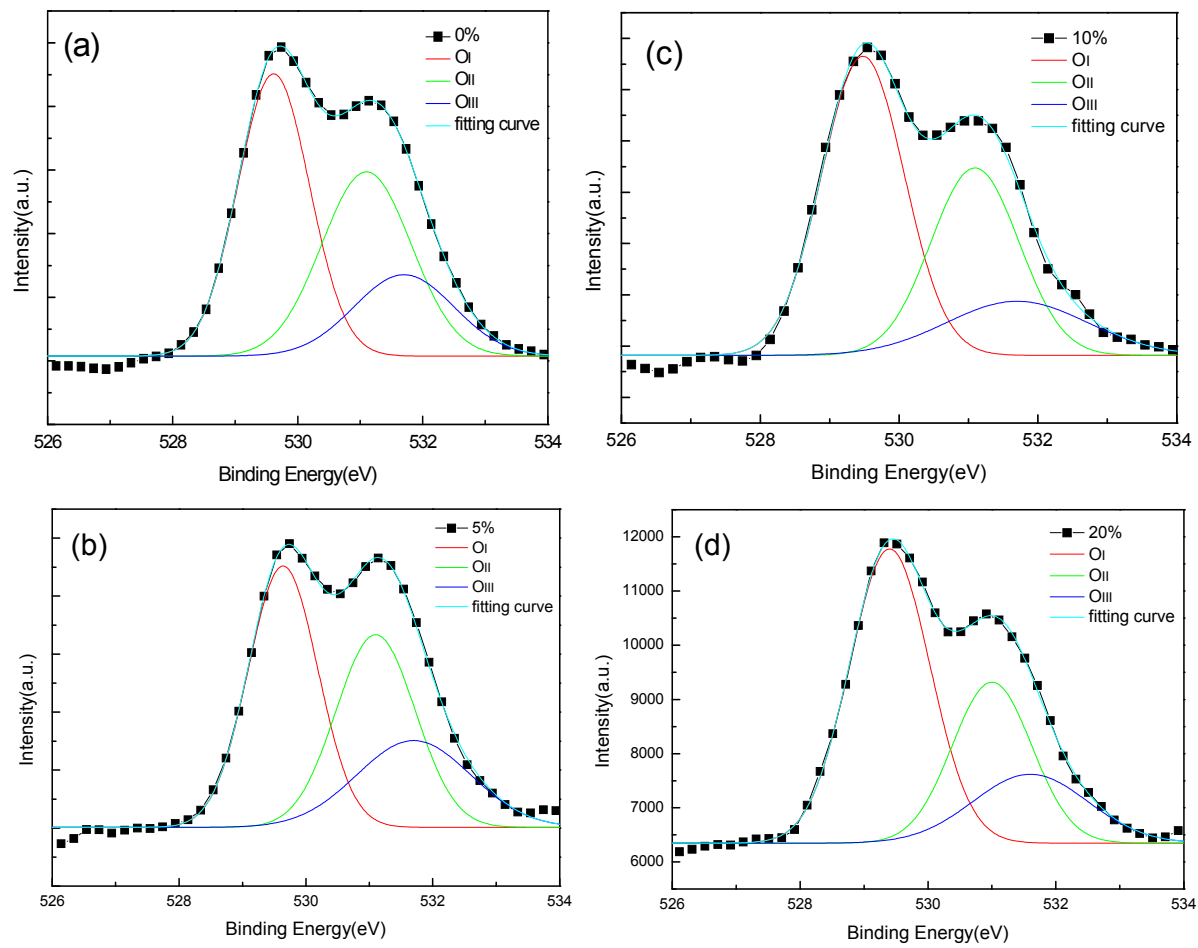

Figure 5. X-ray photoelectron spectroscopy (XPS) spectra of $\mathrm{O}_{1 \mathrm{~s}}$ of IGO film with (a) $0 \%$; (b) 5\%; (c) $10 \%$; and (d) $20 \%$.

The current-voltage characteristics of the IGO photodetector are shown in Figure 6. The dark current of the devices fabricated under $\mathrm{pO}_{2}=5 \%$ and $\mathrm{pO}_{2}=10 \%$ changes linearly with bias from $-10 \mathrm{~V}$ to $10 \mathrm{~V}$, as shown in Figure S2a and Figure S2b of the Supplementary Materials. This indicates that they are ohmic devices. The dark currents for $\mathrm{pO}_{2}=5 \%, 10 \%$, and $20 \%$ are $3.03 \times 10^{-7} \mathrm{~A}, 8.93 \times 10^{-9} \mathrm{~A}$, and $8.1 \times 10^{-12} \mathrm{~A}$ at $10 \mathrm{~V}$ bias, respectively. The small dark current of the $20 \%$ fabricated device is attributed to the high Schottky barrier height and the reduction of the oxygen vacancies in the film. The Schottky characteristic is proved by Figure S3 in the Supplementary Materials. During the photocurrent measurement, the devices were illuminated under $300 \mathrm{~nm}$ UV light. The photocurrents for $\mathrm{pO}_{2}=5 \%, 10 \%$, and $20 \%$ are $5.63 \times 10^{-4} \mathrm{~A}, 1.74 \times 10^{-5} \mathrm{~A}$, and $4.99 \times 10^{-6} \mathrm{~A}$, respectively.

Figure 7 shows the characteristic photoresponse spectra of the photodetector at $10 \mathrm{~V}$ bias. The responsivity can be expressed as:

$$
R=g \frac{\eta q}{h v}
$$

where $\eta$ is the quantum efficiency, $q$ is the electron charge, $h$ is Plank's constant, and $v$ is the frequency of incident light. 
Calculated from Equation (1), the value of $\eta$ is over 100\%, which confirms that there is internal photoconductive gain exhibited by the $5 \%$ and $10 \%$ fabricated devices. Photoconductive gain $(g)$ [17] can also be defined as:

$$
g=\frac{N_{e l}}{N_{p h}}=\frac{\tau_{\text {decay }}}{t_{t r}}
$$

where $N_{e l}$ is the number of electrons collected per unit time, $N_{p h}$ is the number of absorbed photons per unit time, $\tau_{\text {decay }}$ is the hole (minority) lifetime, and $\tau_{t r}$ is the electron transit time.

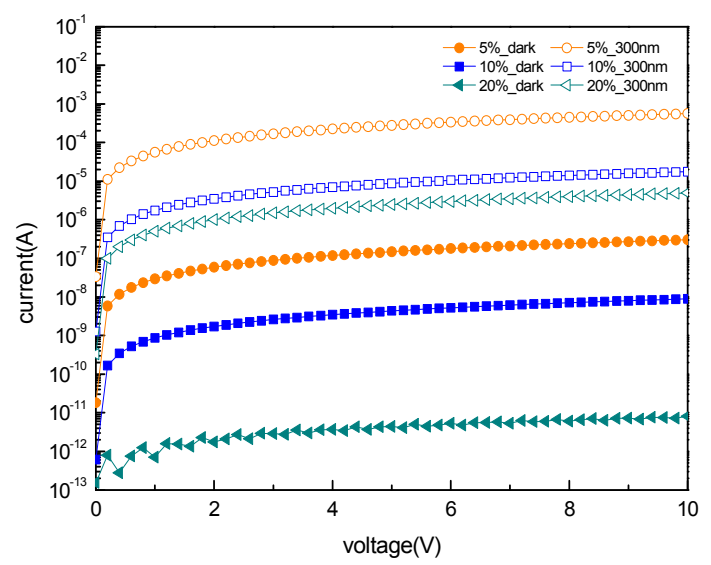

Figure 6. I-V characteristics for $\mathrm{Au} / \mathrm{IGO} / \mathrm{Au}$, with varying oxygen partial pressure.
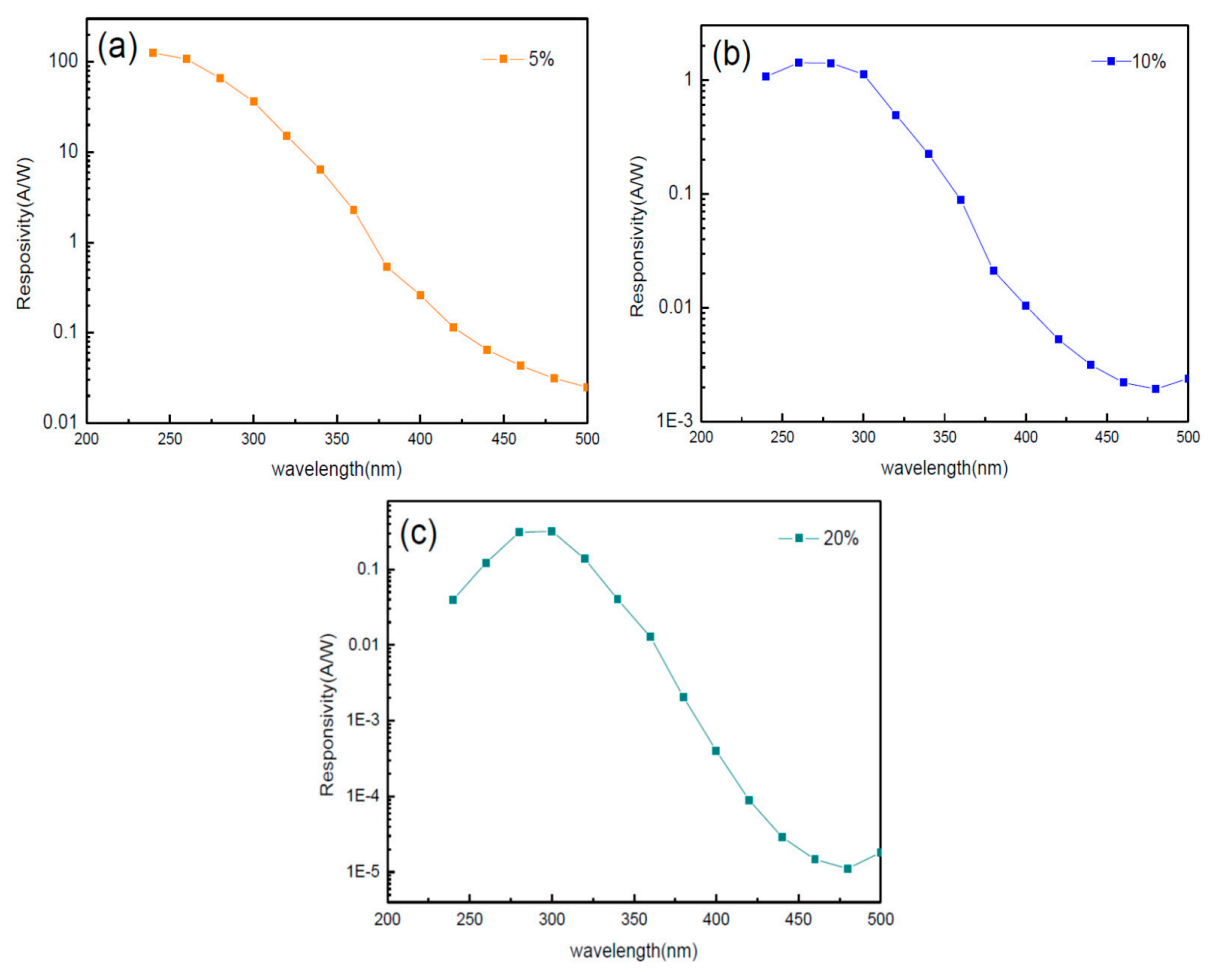

Figure 7. Responsivity of the devices with (a) 5\%; (b) 10\%; and (c) $20 \%$.

Therefore, we know the trapping mechanism plays an important role in the high photoconductive gain [18]. Under $20 \%$ oxygen partial pressure, the trapping phenomenon is modified and its maximum responsivity under $300 \mathrm{~nm}$ illumination is approximately $0.31 \mathrm{~A} / \mathrm{W}$. Table 1 reveals the responsivity of different sensing films fabricated by different methods. As shown in Table 1, the maximum responsivity obtained in this study represents an improvement compared with previous devices. 
Table 1. Maximum responsivity compared with different MSM ultraviolet photodetectors.

\begin{tabular}{cccc}
\hline Sensing Film & Method & Responsivity (A/W) & Reference \\
\hline $\mathrm{MgZnO}$ & Sputter & 0.043 & {$[19]$} \\
$\mathrm{Mg}_{0.18} \mathrm{Zn}_{0.82} \mathrm{O}$ & Sol-gel & 0.27 & {$[20]$} \\
$\mathrm{IGO}$ & Co-sputter & $6.9 \times 10^{-5}$ & {$[14]$} \\
$\mathrm{Ga}_{2} \mathrm{O}_{3}$ & Sol-gel & $8 \times 10^{-5}$ & {$[21]$} \\
$\mathrm{Ga}_{2} \mathrm{O}_{3}$ & MBE & 0.037 & {$[22]$} \\
$\mathrm{Ga}_{2} \mathrm{O}_{3}$ & LMBE & 0.05 & {$[23]$} \\
$\mathrm{In}_{0.9} \mathrm{Ga}_{0.1} \mathrm{O}$ & Sputter & 0.31 & This study \\
\hline
\end{tabular}

Figure 8 shows the photocurrent rise time and decay time under application of $10 \mathrm{~V}$ bias. The $5 \%$ and $10 \%$ device are compared in the same cycles. After the illumination with $300 \mathrm{~nm}$ UV light for $150 \mathrm{~s}$, the photocurrent of $10 \%$ device can reach to maximum current and become stable. When the UV illumination is turned off, the electrons and holes of the $10 \%$ device can recombine in about $200 \mathrm{~s}$. Nonetheless, under the $150 \mathrm{~s}$ illumination, the $5 \%$ device is still at the rising stage. Also, the recombination time of the device is extremely long. This is attributed to the existence of subgap states formed by oxygen vacancies in the film. These subgap states hinder the speed of electron excitation upon UV illumination and recombination when the light is turned off. On the contrary, it can be observed that the $20 \%$ fabricated photodetector shows fast response times, owing to the short lifetime of the carriers. Hence, the rise time and decay time are both apparently improved by increasing oxygen flow. The rise time is defined as the time in which the current rises from $10 \%$ to $90 \%$ of the maximum photocurrent. The decay time is the time in which the current decreases from the maximum photocurrent to the original value. The rise/decay times of $\mathrm{pO}_{2}=20 \%$ are only $21 / 27 \mathrm{~s}$.
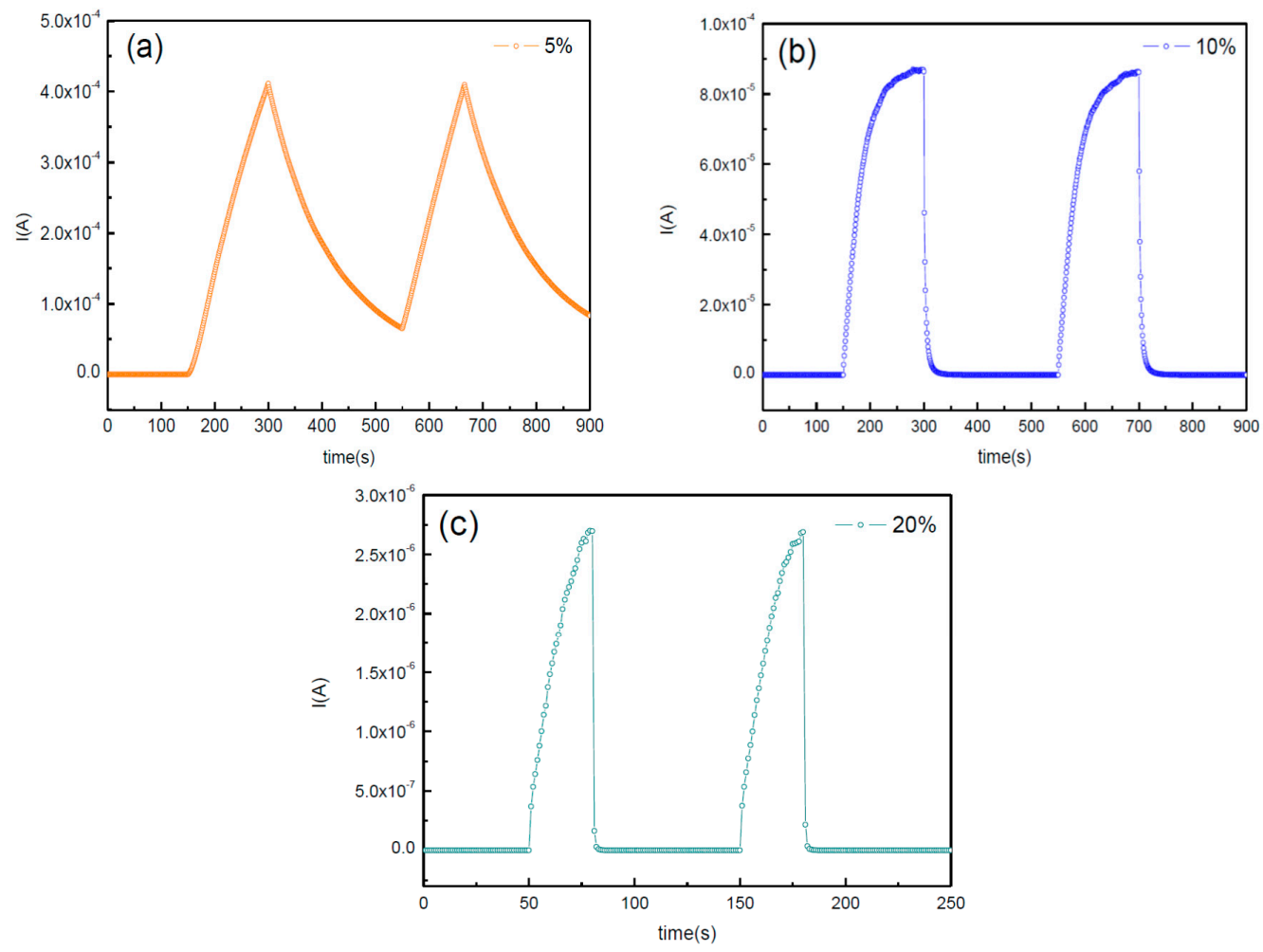

Figure 8. Time-dependent photoresponse of the IGO photodetector with (a) $5 \%$; (b) $10 \%$; and (c) $20 \%$.

Based on the above experimental results and analysis, the band diagram is shown in Figure 9 to explain the whole mechanism. For $5 \%$ and $10 \%$ fabricated devices, although there is sufficient barrier height between $\mathrm{Au}$ and the IGO films, the large number of positively charged oxygen vacancies in the 
interface narrows the depletion region, increasing the probability of electronic transport by tunneling [24]. As a consequence, the dark current is usually larger in the ohmic-type devices. During the illumination, the additional photon energy separates the electrons and holes. The excited electrons tend to move toward the conduction band; however, the vacancies in the film might capture and trap electrons. The large dark current and the trapping mechanism lead to a lower photo/dark current ratio. For the $20 \%$ fabricated device, the defects in the film are restrained, so it becomes a Schottky-type device. During the dark current measurement, the transport process is dominated by thermionic emission of carriers through the barrier; hence, the dark current is apparently reduced. Under UV illumination, the redistribution of space charge gives rise to an increase in positive charge density in the depletion region, causing the barrier to shrink [25]. Therefore, the tunneling probability increases. Both small dark current and the increasing tunneling probability lead to relatively high photocurrent/dark current ratio.

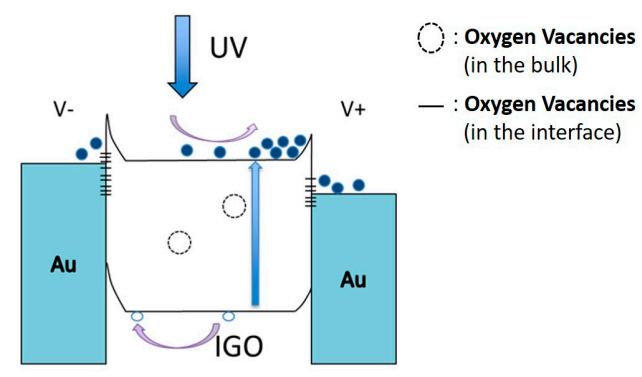

Figure 9. Band diagram of the MSM IGO photodetector under UV light.

\section{Conclusions}

In summary, we investigated the photodetector performance of IGO film as a function of RF-sputtered oxygen partial pressure. For a lower oxygen partial pressure, the devices acted as ohmic-type photodetectors with high internal gain. When deposited at a higher oxygen partial pressure, the devices performed as Schottky-type photodetectors with lower dark current because of the reduction of deficiencies in the film. The responsivity reached $0.31 \mathrm{~A} / \mathrm{W}$. In addition, the photoresponse times of the devices were significantly improved by raising the oxygen partial pressure.

Supplementary Materials: The Supplementary Materials are available online at http:/ /www.mdpi.com/1424-8220/ $16 / 12 / 2145 / \mathrm{s} 1$.

Acknowledgments: This work was supported by the Ministry of Science and Technology under contract number MOST 103-2221-E-006-098 and 105-2221-E-006-118. This work was also supported in part by the Center for Frontier Materials and Micro/Nano Science and Technology, National Cheng Kung University, Taiwan, and by the Advanced Optoelectronic Technology Center, National Cheng Kung University, for projects from the Ministry of Education.

Author Contributions: Sheng-Po Chang, Li-Yang Chang, Jyun-Yi Li conceived and designed the experiments; Sheng-Po Chang, Li-Yang Chang, Jyun-Yi Li performed the experiments; Sheng-Po Chang, Li-Yang Chang, Jyun-Yi Li analyzed the data; Sheng-Po Chang, Li-Yang Chang, Jyun-Yi Li wrote the paper.

Conflicts of Interest: The authors declare no conflict of interest.

\section{References}

1. Muñoz, E.; Monroy, E.; Pau, J.L.; Calle, F.; Omnès, F.; Gibart, P. III Nitrides and UV detection. J. Phys. Condens. Matter 2001, 13, 7115.

2. Pandey, S.K.; Awasthi, V.; Verma, S.; Mukherjee, S. Blue electroluminescence from SbZnO/CdZnO/GaZnO heterojunction diode fabricated by dual ion beam sputtering. Opt. Express 2014, 22, 30983-30991. [CrossRef] [PubMed]

3. Sandvik, P.; Mi, K.; Shahedipour, F.; McClintock, R.; Yasan, A.; Kung, P.; Razeghi, M. $\mathrm{Al}_{\mathrm{x}} \mathrm{Ga}_{1-\mathrm{x}} \mathrm{N}$ for solar-blind UV detectors. J. Cryst. Growth 2001, 231, 366-370. [CrossRef] 
4. Monroy, E.; Omnes, F.; Calle, F. Wide-bandgap semiconductor ultraviolet photodetectors. Semicond. Sci. Technol. 2003, 18, R33-R51. [CrossRef]

5. Guo, F.; Yang, B.; Yuan, Y.; Xiao, Z.; Dong, Q.; Bi, Y.; Huang, J. A nanocomposite ultraviolet photodetector based on interfacial trap-controlled charge injection. Nat. Nanotechnol. 2012, 7, 798-802. [CrossRef] [PubMed]

6. Xie, Y.; Wei, L.; Li, Q.; Chen, Y.; Yan, S.; Jiao, J.; Liu, G.; Mei, L. High-performance self-powered UV photodetectors based on $\mathrm{TiO}_{2}$ nano-branched arrays. Nanotechnology 2014, 25, 075202. [CrossRef] [PubMed]

7. Chen, C.H.; Chang, S.J.; Chang, S.P.; Li, M.J.; Chen, I.C.; Hsueh, T.J.; Hsu, C.L. Novel fabrication of UV photodetector based on $\mathrm{ZnO}$ nanowire/p-GaN heterojunction. Chem. Phys. Lett. 2009, 476, 69-72. [CrossRef]

8. Chen, H.; Liu, K.; Hu, L.; Al-Ghamdi, A.A.; Fang, X. New concept ultraviolet photodetectors. Mater. Today 2015, 18, 493-502. [CrossRef]

9. Sang, L.; Liao, M.; Sumiya, M. A comprehensive review of semiconductor ultraviolet photodetectors: From thin film to one-dimensional nanostructures. Sensors 2013, 13, 10482-10518. [CrossRef] [PubMed]

10. Oshima, T.; Fujita, S. Properties of $\mathrm{Ga}_{2} \mathrm{O}_{3}$-based $\left(\mathrm{In}_{\mathrm{x}} \mathrm{Ga}_{1-\mathrm{x}}\right)_{2} \mathrm{O}_{3}$ alloy thin films grown by molecular beam epitaxy. Phys. Status Solidi C 2008, 5, 3113-3115. [CrossRef]

11. Oshima, T.; Okuno, T.; Arai, N.; Suzuki, N.; Ohira, S.; Fujita, S. Vertical Solar-Blind Deep-Ultraviolet Schottky Photodetectors Based on $\beta-\mathrm{Ga}_{2} \mathrm{O}_{3}$ Substrates. Appl. Phys. Express 2008, 1, 011202. [CrossRef]

12. Ji, Z.; Du, J.; Fan, J.; Wang, W. Gallium oxide films for filter and solar-blind UV detector. Opt. Mater. 2006, 28, 415-417. [CrossRef]

13. Wenckstern, H.V.; Splith, D.; Purfürst, M.; Zhang, Z.; Kranert, C.; Müller, S.; Lorenz, M.; Grundmann, M. Structural and optical properties of $(\mathrm{In}, \mathrm{Ga})_{2} \mathrm{O}_{3}$ thin films and characteristics of Schottky contacts thereon. Semicond. Sci. Technol. 2015, 30, 024005. [CrossRef]

14. Chang, T.H.; Chang, S.J.; Weng, W.Y.; Chiu, C.J.; Wei, C.Y. Amorphous Indium-Gallium-Oxide UV Photodetectors. IEEE Photon. Technol. Lett. 2015, 27, 2083-2086. [CrossRef]

15. Han, S.; Zhang, Z.; Zhang, J.; Wang, L.; Zheng, J.; Zhao, H.; Zhang, Y.; Jiang, M.; Wang, S.; Zhao, D.; et al. Photoconductive gain in solar-blind ultraviolet photodetector based on $\mathrm{Mg}_{0.52} \mathrm{Zn}_{0.48} \mathrm{O}$ thin film. Appl. Phys. Lett. 2011, 99, 242105. [CrossRef]

16. Remashan, K.; Hwang, D.K.; Park, S.D.; Bae, J.W.; Yeom, G.Y.; Park, S.J.; Jang, J.H. Effect of $\mathrm{N}_{2} \mathrm{O}$ plasma treatment on the performance of ZnO TFTs. Electrochem. Solid-State Lett. 2008, 11, H55-H58. [CrossRef]

17. Poti, B.; Todaro, M.T.; Frassanito, M.C.; Pomarico, A.; Passaseo, A.; Lomascolo, M.; Cingolani, R.; De Vittorio, M. High responsivity GaN-based UV detectors. Electron. Lett. 2003, 39, 1747-1749. [CrossRef]

18. Soci, C.; Zhang, A.; Xiang, B.; Dayeh, S.A.; Aplin, D.P.R.; Park, J.; Bao, X.Y.; Lo, Y.H.; Wang, D. ZnO Nanowire UV Photodetectors with High Internal Gain. Nano Lett. 2007, 7, 1003-1009. [CrossRef] [PubMed]

19. Hwang, J.D.; Lin, J.S.; Hwang, S.B. Annealing effects on MgZnO films and applications in Schottky-barrier photodetectors. J. Phys. D Appl. Phys. 2015, 48, 405103. [CrossRef]

20. Yu, J.; Tian, N.; Deng, Y.F.; Zhang, H.H. Ultraviolet photodetector based on sol-gel synthesized MgZnO nanoparticle with photoconductive gain. J. Alloy. Compd. 2016, 667, 359-362. [CrossRef]

21. Kokubun, Y.; Miura, K.; Endo, F.; Nakagomi, S. Sol-gel prepared $\beta-\mathrm{Ga}_{2} \mathrm{O}_{3}$ thin films for ultraviolet photodetectors. Appl. Phys. Lett. 2007, 90, 031912. [CrossRef]

22. Oshima, T.; Okuno, T.; Fujita, S. $\mathrm{Ga}_{2} \mathrm{O}_{3}$ Thin Film Growth on c-Plane Sapphire Substrates by Molecular Beam Epitaxy for Deep-Ultraviolet Photodetectors. Jpn. J. Appl. Phys. 2007, 46, 7217-7220. [CrossRef]

23. Feng, Q.; Huang, L.; Han, G.; Li, F.; Li, X.; Fang, L.; Xing, X.; Zhang, J.; Mu, W.; Jia, Z.; et al. Comparison Study of $\beta-\mathrm{Ga}_{2} \mathrm{O}_{3}$ Photodetectors on Bulk Substrate and Sapphire. IEEE Trans. Electron Devices 2016, 63, 3578-3583. [CrossRef]

24. Guo, D.Y.; Wu, Z.P.; An, Y.H.; Guo, X.C.; Chu, X.L.; Sun, C.L.; Li, L.H.; Li, P.G.; Tang, W.H. Oxygen vacancy tuned Ohmic-Schottky conversion for enhanced performance in $\beta-\mathrm{Ga}_{2} \mathrm{O}_{3}$ solar-blind ultraviolet photodetectors. Appl. Phys. Lett. 2014, 105. [CrossRef]

25. Li, C.; Bando, Y.; Liao, M.; Koide, Y.; Golberg, D. Visible-blind deep-ultraviolet Schottky photodetector with a photocurrent gain based on individual $\mathrm{Zn}_{2} \mathrm{GeO}_{4}$ nanowire. Appl. Phys. Lett. 2010, 97. [CrossRef]

(C) 2016 by the authors; licensee MDPI, Basel, Switzerland. This article is an open access article distributed under the terms and conditions of the Creative Commons Attribution (CC-BY) license (http://creativecommons.org/licenses/by/4.0/). 